\title{
Relatos de violência ocupacional de equipe de enfermagem em uma unidade de emergência no sul do Brasil
}

\author{
Occupational violence experienced by the nursing staff of an emergency care unit in \\ southern Brazil
}

Violencia laboral experimentada por el personal de enfermería de una unidad de cuidados de urgencia en el sur de Brasil

Isaque do Nascimento Germano ${ }^{1 *}$, Caroline Corrêa Gravi ${ }^{1}$, Vanessa Martinhago Borges Fernandes ${ }^{1}$, Elisabeth Flor de Lemos ${ }^{1}$, Eudinéia Luz Schmitz², Ana Bessa Muniz ${ }^{3}$, Ellen Roberta Lima Bessa ${ }^{3}$.

\section{RESUMO}

Objetivo: Descrever diferentes tipos de violência ocupacional vivenciados por uma equipe de enfermagem região sul do Brasil. Métodos: Esta é uma pesquisa qualitativa, descritiva e exploratória, realizada com profissionais de uma Unidade de Pronto Atendimento, no período de março de 2019 a janeiro de 2020, por meio de entrevistas semiestruturadas, submetidos a análise de conteúdo de Bardin. Resultados: Estes foram divididos em 3 categorias: "violência vivenciada", "fatores que contribuem para a perpetuação da violência" e, "a trivialidade da violência no cotidiano dos profissionais de enfermagem", no qual foi verificado que os profissionais de enfermagem estão sofrendo violência rotineiramente, seja por exposição a agressões, seja por negligencias das autoridades e gestores de saúde. Conclusão: Considerando que a violência no trabalho é uma realidade que vem crescendo significantemente a nível mundial, sendo um problema de saúde pública, o estudo mostrou que esta temática precisa ser pesquisada para implementação de estratégias de enfrentamento a favor destes profissionais de saúde.

Palavras-chave: Enfermeiros, Violência no trabalho, Equipe de enfermagem, Enfermagem na emergência, Enfermagem ambulatorial.

\begin{abstract}
Objective: To describe different types of occupational violence experienced by a nursing team in the southern region of Brazil. Methods: This is a qualitative, descriptive and exploratory research, carried out with professionals from an Emergency Care Unit, in the period from March 2019 to January 2020, through semistructured interviews, submitted to Bardin's content analysis. Results: These were divided into 3 categories: "experienced violence", "factors that contribute to the perpetuation of violence" and, "the triviality of violence in the daily lives of nursing professionals", in which it was verified that nursing professionals are suffering violence routinely, either by exposure to aggression, either by negligence of health authorities and managers. Conclusion: Considering that violence at work is a reality that has been growing significantly worldwide, being a public health problem, the study showed that this theme needs to be researched for the implementation of coping strategies in favor of these health professionals.
\end{abstract}

Keywords: Nurses, Workplace violence, Nursing team, Emergency nursing, Outpatient nursing.

\section{RESUMEN}

Objetivo: Describir diferentes tipos de violencia laboral experimentada por un equipo de enfermería de la región sur de Brasil. Métodos: Se trata de una investigación cualitativa, descriptiva y exploratoria, realizada con profesionales de una Unidad de Atención de Urgencias, en el periodo comprendido entre marzo de 2019 y enero de 2020, mediante entrevistas semiestructuradas, sometidas al análisis de contenido de Bardin. Resultados: Se dividieron en 3 categorías: "violencia experimentada", "factores que contribuyen a la

1 Universidade do Sul de Santa Catarina (UNISUL), Palhoça - SC. *E-mail: isaquegermano@hotmail.com

2 Hospital Regional de São José Dro Homero de Miranda Gomes, São José - SC.

3 Universidade Estadual Paulista (UNESP), São José dos Campos - SP. 
perpetuación de la violencia" y, "la trivialidad de la violencia en el día a día de los profesionales de la enfermería", en las que se comprobó que los profesionales de la enfermería están sufriendo violencia de forma rutinaria, ya sea por la exposición a las agresiones, ya sea por la negligencia de las autoridades y gestores sanitarios. Conclusión: Considerando que la violencia en el trabajo es una realidad que está creciendo significativamente a nivel mundial, siendo un problema de salud pública, el estudio muestra que esta temática debe ser investigada para implementar estrategias de enfrentamiento a favor de los profesionales de la salud.

Palabras clave: Enfermeros, Violencia en el trabajo, Equipo de enfermería, Enfermería en urgencias, Enfermería ambulatoria.

\section{INTRODUÇÃO}

A violência no trabalho, tem ocupado um lugar de destaque nos riscos ocupacionais, principalmente acometido profissionais da saúde, o qual vem sendo recorrente a cada dia mais, sendo considerado um problema de saúde pública. Os relatos de violência nos ambientes onde são realizadas prestações de serviços de cuidados à saúde são preocupantes, sendo estas uma realidade em vários países, indiferentes das características econômicas ou culturais (FERNANDES H, et al., 2018, SILVA ACA, et al., 2018).

A Declaração Universal dos Direitos Humanos de 1948, garante no artigo 23 que: "Toda pessoa tem direito ao trabalho, à livre escolha de emprego, a condições justas e favoráveis de trabalho". No Brasil, os profissionais são amparados pela Constituição Federal, garante que "Todos têm o direito ao meio ambiente ecologicamente equilibrado, bem de uso comum do povo e essencial à sadia qualidade de vida" (ORGANIZAÇÃO DAS NAÇÕES UNIDAS (ONU), 1948, BRASIL, 1988).

A Organização Mundial de Saúde (OMS) define que o ato de violência é prejudicar a si ou o próximo usando força física, ações ou ameaças que causem ou possam causar lesões, morte, danos psicológicos, alterações no desenvolvimento ou privação (OMS, 1998). Não existe um consenso que traga uma definição exata de violência no trabalho, e ainda existem lacunas nos estudos e nos termos utilizados para se referir a este tema, porém segundo a Organização Internacional do Trabalho (OIT) "violência e assédio" no local de trabalho, é a ação constante de comportamentos e práticas inaceitáveis que parte do agressor, gerando sofrimentos, danos físicos, psicológicos ou sexuais ao profissional (KRUG EG, et al., 2002; OIT, 2018).

Neste cenário, violência ocupacional é retratado como qualquer ato praticado contra o profissional no seu espaço de trabalho, causando danos físicos ou psíquicos relacionados com a segurança e saúde do profissional (OCCUPATIONAL SAFETY AND HEALTH ADMINISTRATION (OSHA), 2021). Segundo a OSHA entre 2011 e 2013, as violências nos locais de trabalho norte-americano variaram de 23.540 e 25.630 casos por ano, chegando de $70 \%$ a $74 \%$ ocorrendo nos serviços de saúde, incluindo os serviços sociais (OSHA, 2021).

Apesar da importância destas profissões, com atribuições específicas voltada ao cuidar do próximo, traz consigo um alto risco à saúde dos profissionais, uma vez que a frequente exposição aos diversos problemas ofertados pelo labor, afeta a todos. A violência no ambiente de trabalho afeta todos os setores, incluindo os profissionais de Enfermagem, sendo uma realidade global, ocorrendo em países desenvolvidos ou não, e em vários tipos de trabalho e grupos ocupacionais (PEDRO DRC, 2017; GEOFFRION S, 2020; LI M, 2020).

O Conselho Regional de Enfermagem (COREN) de São Paulo, realizou uma pesquisa com profissionais de enfermagem e evidenciou que cerca de $54,7 \%$ destes já sofreram algum tipo de violência no seu ambiente de trabalho, sendo atos de violência verbal, física e psicológica, praticados pelos pacientes, familiares, colegas de profissão e superiores, destes $64,9 \%$ não realizaram nenhum tipo de denúncia (COREN 2021).

Partindo do pressuposto onde este grupo profissional é de grande importância na equipe de saúde, sendo o quadro atual de violência, esta pesquisa buscou desvelar os principais problemas e dificuldades enfrentados pela equipe de enfermagem, verificando a interferência direta na saúde e no desempenho deste profissional, traçando assim, o perfil do quadro atual da violência, sendo base para futuras ações voltadas ao combate destes atos nestas unidades. Diante dos fatos mencionados, este estudo objetivou-se verificar os tipos de 
violência ocupacional que acometem a equipe de enfermagem em uma Unidade de Pronto Atendimento em um Município da região Sul do Brasil, compreendendo os diferentes tipos de agressão enfrentadas pelos componentes da equipe.

\section{MÉTODOS}

Esta é uma pesquisa de abordagem qualitativa, do tipo descritiva e exploratória, que foi realizada com profissionais de enfermagem de uma Unidade de Pronto Atendimento, localizada no Estado de Catarina, na região Sul do Brasil.

A população total da unidade componha 30 profissionais, porém destes participaram da pesquisa 23 profissionais de enfermagem, utilizou-se como critério de inclusão: ser profissional de nível técnico ou superior de enfermagem, estar atuando na instituição (UPA) por no mínimo 30 dias, nos turnos diurno e/ou noturno. Como critérios de exclusão foi utilizado os profissionais que estavam afastados por quaisquer motivos, algum tipo de licença ou aqueles que não aceitaram participar a pesquisa.

Após o convite, aceite, entendimento e preenchimento de todos os termos éticos previstos, os dados dos participantes foram coletados utilizando-se a técnica de entrevista semiestruturada, seguindo roteiro prévio, aplicado por um único pesquisador anteriormente treinado e calibrado.

As entrevistas foram realizadas na sala da coordenação de enfermagem do local de pesquisa, preservando a privacidade dos participantes. O período da coleta de dados foi de março 2019 a janeiro de 2020, conforme a disponibilidade dos participantes. Para garantir a qualidade e fidedignidade dos dados, as entrevistas também foram gravadas em áudio mediante a autorização, respeitando o tempo necessário de cada um e posteriormente transcritas. Para manter o anonimato dos entrevistados, os mesmos foram identificados como: Profissional (P) seguido de numeral em ordem crescente de 1 a 23 (Ex.: P1, P2, P3 etc.).

Para análise dos resultados, utilizou-se a técnica de Análise de Conteúdo de Laurence Bardin (BADIM, 2011) no qual é um conjunto de técnicas de análise das comunicações, que permite evidenciar a presença ou a ausência de determinado fenômeno a partir da mensagem comunicada pelos sujeitos, assim, análise de conteúdo deve ser organizada através de três fases: a primeira é a fase de organização, visa estabelecer contato com os documentos a analisar e em conhecer o texto deixando-se invadir por impressões e orientações; a segunda é a fase em que serão feitas as "operações de codificação, decomposição ou enumeração, em função de regras previamente formuladas"; enfim, a terceira fase é onde consiste em tornar os dados significativos e válidos através da criação de quadros de resultados para propor inferências e interpretações de acordo com os objetivos propostos.

O estudo foi aprovado pelo Comitê de Ética em Pesquisa da Universidade do Sul de Santa Catarina, com parecer consubstanciado CAAE 04854818.6.0000.5369 e respeitou os aspectos éticos da resolução $\mathrm{n}$. 466/2012 (BRASIL, 2012). Todos os participantes do estudo assinaram o Termo de Consentimento Livre e Esclarecido e foram identificados por codinomes de deuses gregos escolhidos pelos pesquisadores, para preservar suas identidades.

\section{RESULTADOS}

O estudo foi realizado com 23 profissionais de enfermagem, composto por 8 enfermeiros, sendo 7 do sexo feminino e 1 do sexo masculino e 15 técnicos de enfermagem, sendo 9 do sexo feminino e 6 do sexo masculino, na faixa etária de 25 e 46 anos. Dentre os enfermeiros entrevistados, 3 possuem especialização em Urgência e Emergência, 3 em Saúde da Família e 1 em Enfermagem do Trabalho. Dentre os quinze técnicos, 5 possuem curso de capacitação em Urgência e Emergência. Em relação ao tempo de atuação dos profissionais na instituição, este variou entre 2 meses e 3 anos. Dos 23 entrevistados, 13 possuem mais de um vínculo empregatício para compor sua renda mensal.

A partir da análise de dados, e para uma melhor compreensão, foi construída três categorias: "Violência vivenciada", "Fatores que contribuem para a perpetuação da violência" e "A trivialidade da violência no cotidiano dos profissionais de enfermagem". 


\section{Violência Vivenciada}

Desta categoria surgiu duas subcategorias: "violência vivenciada pelos profissionais de enfermagem" e "violência presenciada pelos profissionais de enfermagem".

\section{Violência vivenciada pelos profissionais de enfermagem}

Seguindo o roteiro de entrevista, foi realizado a seguinte pergunta "Você já sofreu algum tipo de violência no seu ambiente de trabalho?", a partir desta, os participantes puderam externar suas vivências em relação ao assunto. Vários tipos de violência foram mencionados, dentre elas: verbal que foi predominante entre os participantes; física; ameaça; abuso da chefia e assédio moral, conforme os relatos abaixo:

“[...] Geralmente é porque eles estão impacientes, não querem esperar ou discordam da conduta, aí eles querem questionar, e se alguém vai explicar como funciona como tem que ser feito, eles não aceitam e querem que seja feito do jeito deles e acabam se alterando e agredindo verbalmente" ( $\mathrm{P} 1$, violência verbal).

"[...] Já levei tapa de paciente, estava eu e outra enfermeira, ele jogou a lixeira na gente, é grande daquelas de inox, porque ele dizia que tinha uma coisa e ela relatou na classificação de risco, só que ela o colocou em azul e ele não admitiu" (P2, violência física).

"[...] Foi por uma de uma ameaça que a paciente fez para a enfermeira, aí eu fui 'ajudar', se não ela poderia ter apanhado, aí o marido que era o acompanhante nos ameaçou de morte, aí a gente parou na delegacia" (P3, ameaça de morte).

"[...] A chefia ela era simplesmente abusiva, ela continua sendo até hoje uma pessoa assim, horrivel, acredito que vai pagar todos os pecados antes de morrer, porque ela é uma pessoa que manipulava as outras sabe, ela não via o seu trabalho, ela via o que ela queria ver" (P2, abuso da chefia).

"[...] Tu sai da triagem, seja para ir tomar água, ir ao banheiro ou ir resolver algum problema, tem paciente que diz 'tá o expediente já acabou?', 'o salário deve está atrasado né, porque ninguém quer trabalhar', tu sofre esse tipo de violência não todos os dia, não é diariamente, isso machuca a gente" (P4, assédio moral).

\section{Violência presenciada pelos profissionais de enfermagem}

A grande maioria dos participantes além de terem sofrido a violência, também presenciaram em algum momento outros colegas de profissão sendo violentados, conforme o relato abaixo:

"[...] Sim, já teve outros aí que já foram para delegacia, a noite acontece bastante, como eu sou mais do diurno, é questão de bate-boca, qualquer coisinha já está chamando a polícia que tá demorando não sei o que, aí já teve outras agressões aqui, com outras pessoas, capacete na cabeça e etc., ai foram todos para delegacia” (P5, presenciando a violência).

\section{Fatores que contribuem para a perpetuação da violência}

Esta categoria originou três subcategorias: "ambiente de trabalho violento", "profissionais expostos a todos os tipos de paciente" e "falta de informação dos usuários".

\section{Ambiente de trabalho violento}

O primeiro fator levantado pelos participantes é que o ambiente de trabalho é caracterizado como violento, pois as situações que levam as pessoas a estarem naquele ambiente, são urgência e emergência, faz com que o humor seja alterado, assim como sentimentos e emoções levam a atitudes impensadas e inapropriadas, sem haver segurança para os profissionais, conforme o relato abaixo:

"[...] É um ambiente extremamente violento para trabalhar, não dá para dizer que não, a gente já foi ameaçada de morte aqui dentro, o paciente diz que vai matar todo mundo se não atenderem ele" (P6, ambiente de trabalho violento). 


\section{Profissionais expostos a todos os tipos de paciente}

O segundo fator que contribui para a violência contra os profissionais, é exposição a vários tipos de paciente em diversas situações, conforme os relatos abaixo.

"[...] O problema é que no dia seguinte ele voltou, só que daí a queixa é que ele tinha feito o uso de medicamentos em grandes quantidades de psicotrópicos, foi comunicado a coordenação, tudo é relatado e fica no livro ATA" (P7, paciente em uso de medicamentos).

"[...] Um rapaz que chegou baleado, ele foi retirado do carro e aí eu fui pegar a maca aqui dentro para colocar ele, aí ele entrou correndo dizendo, onde que tu vai? Por que tu não está aqui? Tu estás deixando de salvar uma vida" (P2, paciente baleado).

\section{Falta de informação dos usuários}

O terceiro fator que contribui para a violência, é falta de informação dos usuários em relação a classificação de risco e os procedimentos adotados pelos profissionais, que faz com que as pessoas não sejam atendidas pela ordem de chegada, e sim, pela ordem de prioridade. Levando os pacientes a realizarem a violência, conforme relatos abaixo:

"[...] As pessoas não têm a real noção do funcionamento dos serviços, do cronograma da emergência, então as pessoas na maioria das vezes por ignorância, elas acham que a gente não quer trabalhar" (P8, falta de informações do usuário).

"[...] É que o povo não sabe como é que funciona, não sabe que a enfermagem depende do médico, que a enfermagem não pode chegar lá e pegar e vem cá que eu vou te atender, vou te dar esse remédio aqui e acabou" (P2, falta de informação do usuário).

\section{A trivialidade da violência no cotidiano dos profissionais de enfermagem}

Desta categoria, foi criado quatro subcategorias para expor como a violência se tornou algo corriqueiro no ambiente de trabalho dos profissionais de enfermagem. As subcategorias são: "Violência no cotidiano dos profissionais de enfermagem", "Aceitação da violência por parte de alguns profissionais de enfermagem", "Falta de apoio institucional com os profissionais de enfermagem" e "Consequências do ato de violência para os profissionais de enfermagem".

\section{Violência no cotidiano dos profissionais de enfermagem}

Esta subcategoria mostra como é frequente a prática de violência no cotidiano dos profissionais de enfermagem, conforme os relatos abaixo:

"[...] É uma situação que não se espera né, porque no local de trabalho tu estas para trabalhar e não receber xingamentos, isso aí não é a primeira vez e não vai ser a última que vai acontecer todo dia, sempre acontece só que bola para frente" (P9, violência no cotidiano).

“[...] Agressão física não, mas verbal a gente recebe praticamente todos os dias, então tem que vir e fazer nosso papel e saber que estamos expostos isso, mas a gente chega aqui do mesmo jeito para atender todos os dias" (P10, violência no cotidiano).

\section{Aceitação da violência por parte de alguns profissionais de enfermagem}

Seguindo o roteiro de entrevista, foi feito um questionamento para os participantes, "se eles tinham realizado algum tipo de denúncia após terem sofrido a violência". Uma grande parte dos participantes sofre violência com frequência, banalizando este fenômeno, não dando a devida importância e, por consequência, não realizando denuncia, conforme o relato abaixo: 
“[...] Não, porque não se estendeu, se tivesse se estendido ou causado danos ao patrimônio ou sido agressão física, porque isso aqui na UPA acontece e é bem comum, então acaba passando batido" (P11, aceitação da violência).

\section{Falta de apoio institucional com os profissionais de enfermagem}

Outro questionamento realizado com os participantes da pesquisa foi: "como a instituição procedeu após a violência?", a grande maioria dos entrevistados desconhecem algum protocolo institucional que ajude nos casos de violência contra os profissionais, conforme o relato:

“[...] Nunca ouvi falar, se existe eu nunca ouvi falar” (P12, desconhece protocolo).

Esses profissionais, além de desconhecerem protocolos que possam ajudar em casos de violência, negam também apoio da instituição para lidar com a situação, conforme o relato:

"[...] Só foi passado para a chefia, não foi feito nenhum documento" (P13, falta de apoio institucional).

\section{Consequência do ato violência para os profissionais de enfermagem}

As práticas da violência contra os profissionais desencadeiam vários problemas, resultando em problemas físicos, psicológicos ou prejuízos a equipe de enfermagem, conforme os relatos abaixo:

"[...] De repente tu está fazendo teu trabalho e te agridem verbalmente como se todos os problemas da unidade fosse culpa tua, sempre tem aquele medo de que a violência verbal vire física, então a partir do momento que tu é agredida, tu fica com taquicardia e com dor de cabeça" (P6, consequência física).

"[...] Meus colegas chegaram a ficar com depressão, colegas chegam a ser afastados, chegam a ter crise de pânico porque as pessoas ameaçam que vão pegar na rua, então isso prejudica muito a nosso trabalho" (P8, consequência para equipe de enfermagem).

\section{DISCUSSÃO}

A maior parte dos participantes deste estudo já sofreu algum tipo de agressão, sendo prevalentes e frequentes. Estes resultados vêm ao encontro com os achados de alguns autores, que evidenciam que a grande maioria dos profissionais de enfermagem vivenciaram ou sofreram violência no seu ambiente de trabalho, sendo a violência verbal o tipo mais predominante, por estarem em constante contato direto com os pacientes (FREITAS RJM, et al., 2017).

Outro estudo ao quantificar violência psicológica (verbal, ameaças, assédio de pacientes e chefia), demonstrou e confirmou também estes achados onde, apresentou uma alta prevalência destes eventos chegando a 135 dos 227 casos registrados, precedido de violência física que apresentou 42 eventos registrados (SCARAMAL DA, et al., 2017). É válido ressaltar que alguns destes sofreram mais de um tipo de violência.

Há vários fatores que podem contribuir para que isto ocorra, a sobrecarga de atividades e a superlotação em Unidades de Saúde gera em si conflitos entre trabalhadores e usuários, além disso, isto está ligado ao processo de trabalho, que vai desde a demora no atendimento, as condições do paciente, dos tipos de relacionamentos, problemas na comunicação, disputa de poder, hierarquia e as condições de trabalho (SCARAMAL DA, et al., 2017).

Estes fatores cooperam para que se sintam desprotegidos no processo de trabalho, por isso, nos últimos anos a violência nas instituições de saúde, tem se tornado alvo de debates entre os sindicatos trabalhistas, pois independente da área de atuação, estes sentem-se inseguros e à mercê das agressões, principalmente em tempos de pandemia, onde a violência e discriminação contra profissionais de saúde têm sido cada vez mais comum (PAI DD, et al., 2018; CONTRERAS J, et al., 2020). Assim como a falta de leitos e alta demanda 
de pacientes gera ainda mais conflitos para enfermeiros ligados aos processos de urgências e emergências centros de saúde (AYDOGDU ALF, 2020).

Incentivos para notificar a violência, respostas aos agressores e orientações da instituição aos profissionais de enfermagem acerca das medidas a serem tomadas diante do ato de violência, reduziria os casos de agressões no ambiente de trabalho e daria mais visibilidade a violência perpetuada (FONTANA RT, 2019). Visto que, todos as vítimas de violência esperam receber suportes institucional, que contempla apoio emocional e jurídico, em alguns países como a China e Austrália já são realidade, porém, o Brasil não apresenta (ZHAO S, 2016).

Porém, realidade que este estudo demonstrou é que além não receberem nenhum tipo de suporte institucional, assim, pôde-se constatar que realizar uma denúncia formal não é uma rotina efetuada por estes. Isto é o resultado da falta de encorajamento por parte dos gestores e pela ausência de programas voltados ao combate e prevenção da violência, também por não possuem estratégias baseadas em evidências como lidar com esse tipo de problema (HOGARTH KM, 2015)

Como mecanismo de defesa, uns reclusam-se e calam-se, outros optam pela comunicação, como uma alternativa de resiliência, no sentido conscientizar o agressor, a fim de evitar a violência (SCARAMAL DA, 2017). Em contrapartida outros toleram devido à condição de saúde do paciente, entendendo que a atitude violenta dos pacientes ou acompanhantes resulta da não aceitação da doença e do tratamento indicado (ALMEIDA HRF, 2019).

Dos que sofrem agressão verbal não registraram boletim de ocorrência na delegacia de polícia ou abriram processo judicial contra o agressor, mostrando um total desinteresse ou desesperança. Isto também demonstra que consideram a violência psicológica algo de menor impacto e que isto faz parte do cotidiano de trabalho (PAULA GS, et al., 2017)

Esses profissionais reconhecem que estão expostos a todos os tipos de violência, e esses eventos trazem consigo graves consequências na vida pessoal e profissional de cada um. Devido à natureza dessas ações, a equipe de enfermagem acaba sofrendo desgaste em relação as suas atribuições, resultando no adoecimento desses trabalhadores (PAI DD, et al., 2018). Além de vulnerabilidades físicas estes também manifestam sentimentos de irritabilidade, raiva, tristeza, baixa autoestima, frustração, humilhação e medo, além da sensação de impotência e insegurança, esses sentimentos e emoções contribuem para surgimento de dores, ansiedade e alterações somáticas, além disso, os profissionais podem ficar mais tensos e abalados no trabalho, desempenhando suas funções com menor satisfação (BORDIGNON e MONTEIRO MI, 2016).

Ademais, a violência no trabalho da enfermagem pode alterar o modo de atendimento, resultando em distanciamento, desmotivação, hostilização, desatenção, tornando ineficaz o processo de trabalho e desempenho (FONTANA RT, 2019). A violência no cotidiano dos profissionais de saúde transformar e pode alterar a essência da profissão que se dá pela "arte do cuidado", acarretando aos profissionais o sentimento de desvalorização e questionamento da importância da profissão.

\section{CONCLUSÃO}

Com base no objetivo deste estudo constatamos alta prevalência de violência ocupacional acometendo os profissionais de enfermagem da unidade pesquisada. Em conclusão averiguamos que apesar da exposição rotineira a todo tipo de agressão, estes suportavam de forma calada e eram negligenciados por seus superiores, tais como, gestores da unidade e gestores de saúde em geral. Outro ponto verificado foi que as autoridades locais não levavam em consideração as denúncias realizadas por eles. Portanto os profissionais desta unidade estão sofrendo de forma contínua agressões que afetam diretamente sua saúde física e mental, além da desmotivação no ambiente de trabalho.

\section{AGRADECIMENTOS}

Agradecemos a Equipe de Enfermagem da Unidade de Pronto Atendimento pela compreensão e colaboração conosco. 


\section{REFERÊNCIAS}

1. ALMEIDA HRF. Repercussões da violência ocupacional na saúde dos profissionais de enfermagem. Revista Recien, 2019; 27(4):4-12.

2. AYDOGDU ALF. Violência e discriminação contra profissionais de saúde em tempos de novo coronavírus / Violence and discrimination against healthcare workers in times of new coronavírus J. nurs. health, 2020; 10(4): 20104006.

3. BARDIN L. Análise de conteúdo. Edição revista e atualizada, São Paulo: edições 70, 2011; 279.

4. BORDIGNON M, MONTEIRO MI. Violência no trabalho da Enfermagem: um olhar às consequências: um olhar às consequências. Rev. Bras. Enferm, 2016; 69(5):996-999.

5. BRASIL. Governo Federal. Constituição da República Federativa do Brasil. 1988. Disponível em: http://www.planalto.gov.br/ccivil_03/constituicao/constituicaocompilado.htm. Acessado em 04 de janeiro de 2021.

6. CONTRERAS $\mathrm{J}$ et al. Violencia en el trabajo hacia los profesionales de enfermería en los servicios de emergencias: revisión integrativa. Rev Panam Salud Publica. 2020; 44(1):173.

7. CONSELHO REGIONAL DE ENFERMAGEM (COREN). Sondagem com médicos e profissionais de enfermagem. São Paulo, 2017. Disponível em: http://portal.coren-sp.gov.br/sites/default/files/Pesquisa.pdf\#overlay-context=. Acessado em 10 de janeiro de 2021.

8. FERNANDES H, et al. Violence in health care settings: rethinking actions. Rev Bras Enferm, 2018;71(5):2599-601.

9. FONTANA RT. A violência no cotidiano de trabalho da enfermagem e os usos de si no enfrentamento. Vivências, 2019; 16(30): 99-114.

10. FREITAS RJM, et al. A violência contra os profissionais da enfermagem no setor de acolhimento com classificação de risco. Rev. Gaú. Enferm, 2017; 38(3):1-8.

11. GEOFFRION S, et al. Education and training for preventing and minimizing workplace aggression directed toward healthcare workers. Cochrane Database of Systematic, 2020; 9:(8).

12. HOGARTH KM, et al. Atitudes dos enfermeiros em relação à denúncia de violência no pronto-socorro. Aust. Emerg. Nurs. J., 2015; 19(2): 75-81.

13. KRUG EG, et al. World report on violence and health. Geneva, World Health Organization, 2002. Disponível em: https://apps.who.int/iris/handle/10665/42495. Acessado em 04 de janeiro de 2020.

14. LI M, et al. The relationship of workplace violence and nurse outcomes: Gender difference study on a propensity score matched sample. J Adv Nurs. 2020;76(2): 600-610.

15. ORGANIZAÇÃO INTERNACIONAL DO TRABALHO (OIT). Acabar com a violência e o assédio contra mulheres e homens no mundo do trabalho. 2018. Disponível em: https://www.ilo.org/wcmsp5/groups/public/---ed_norm/--relconf/documents/meetingdocument/wcms630695.pdf. Acessado em 6 de janeiro de 2021.

16. ORGANIZAÇÃO MUNDIAL DA SAÚDE (OMS). Relatórios diversos, 1998. Disponível em: https://www.who.int/eportuguese/publications/pt/. Acessado em 04 de janeiro 2021.

17. ORGANIZAÇÃO DAS NAÇÕES UNIDAS (ONU). Declaração Universal dos Direitos Humanos (1948). Disponível em: http://www.pge.sp.gov.br/centrodeestudos/bibliotecavirtual/instrumentos/2decla.htm\#: :text=Artigo\%20XXIII\%20\%2D $\% 201$. Acessado em 4 de janeiro de 2021.

18. OCCUPATIONAL SAFETY AND HEALTH ADMINISTRATION (OSHA). Guidelines for Preventing Workplace Violence for Healthcare and Social Service Workers. Disponível em: https://www.osha.gov/Publications/osha3148.pdf. Acessado em 10 de janeiro de 2021.

19. PEDRO DRC, et al. Violência ocupacional na equipe de enfermagem: análise à luz do conhecimento produzido. Saúde debate [Internet], 2017:41(113): 618-629.

20. SILVA ACA, et al. A prática da violência voltadas aos profissionais da Enfermagem. Rev. Dialog. Int., 2018; 2(7): 100108.

21. SCARAMAL DA, et al. Occupational physical violence in urgency and emergency hospital services: perceptions of nursing workers: perceptions of nursing workers. Reme: Rev. Min. Enferm., 2017; 21(1): 1-8

22. PAI DD, et al. Violência Física E Psicológica Perpetrada No Trabalho Em Saúde. Tex. \& Cont. Enfermagem., 2018; 27(1): 1-10.

23. PAULA GS, et al. Violência relacionada ao trabalho na psiquiatria. Smad Ver. El. Saú. Men. Ál. Drog,, 2017; 14(2):8692.

24. ZHAO S, et al. Violence against General Practitioners and Nurses in Heilongjiang Province, China: social supports and prevention strategies. Social Supports and Prevention Strategies. Plos One, 2016; 11(6):1-14. 